\title{
Closure of the Ductus Arteriosus and Mechanics of Breathing in Preterm Infants after Surfactant Replacement Therapy ${ }^{1}$
}

\author{
GREGORY P.. HELDT, ERKKI PESONEN, T. ALLEN MERRITT, WILLIAM ELIAS, AND \\ DAVID J. SAHN
}

Department of Pediatrics [G.P.H., E.P., T.A.M., W.E., D.J.S.], University of California Medical Center, San Diego, CA 92103, and Department One of Pediatrics [E.P.], University Central Hospital, Helsinki, Finland

\begin{abstract}
Treatment of premature infants with exogenous surfactant is thought to increase the incidence of the patent ductus arteriosus (PDA) due to improved mechanics of breathing and the resultant reduced pulmonary vascular resistance. As part of a prospective, blinded, controlled study of human amniotic fluid-derived surfactant, we assessed the time of closure of the PDA, defined by Doppler echocardiographic studies, performed at 6-h intervals, and the mechanics of breathing at 6,18 , and $30 \mathrm{~h}$ of age in 61 infants (gestational age, 25-29 wk, and birth wt, 450-1580 g). All infants had respiratory distress syndrome as confirmed by immature surfactant phospholipid profiles determined on either amniotic fluid and/or tracheal aspirate analysis, and chest radiograph, and all had a PDA at $6 \mathrm{~h}$ of age. Surfactant treatment was associated with more frequent clinically determined need for treatment of the PDA, but did not prolong the patency of the ductus in infants with spontaneous closure or in those requiring treatment with indomethacin. Infants with spontaneous closure of the PDA had significantly higher dynamic lung compliances and lower oxygen requirements and were treated with lower mean airway pressures than those requiring PDA treatment, although their arterial blood gas status was the same. The dynamic lung compliance of infants with right to left ductal shunting was significantly lower than those with left to right shunting at 6 and $18 \mathrm{~h}$ but was not different thereafter. This study suggests that the maturity of the ductus arteriosus, reflected by its tendency to close spontaneously, parallels the maturity of the lungs, reflected by their mechanical stability, and that ductal closing is not significantly altered by surfactant therapy. (Pediatr Res 25:305-310, 1989)
\end{abstract}

\section{Abbreviations}

RDS, respiratory distress syndrome

PDA, patent ductus arteriosus

$\mathbf{a} / \mathbf{A}$, arterial to alveolar oxygen tension ratio

Treatment of preterm infants with exogenous surfactant has been proposed as a means to reduce the severity and complications of RDS. Infants treated with surfactant have improvement

Received July 27, 1988; accepted November 8, 1988.

Correspondence Gregory P. Heldt, M.D., UCSD Medical Center, H-638-A, 225 W. Dickinson Street, San Diego, CA 92103.

Supported in part by Finnish Academy, The Finnish Cultural Fund, The Paulo Foundation and Bernhard Landtman Foundation, and USPHS Grant HL-35036.

${ }^{1}$ Presented in part before the Society for Pediatric Research, Washington, DC, May 1988. in oxygenation and reduction in ventilatory pressures (1-5), which suggests that the surfactant reaches the distal air spaces, reduces the alveolar surface tension, and improves the mechanics of breathing.

Early reports of surfactant treatment suggested that symptoms of the PDA were more frequent after surfactant treatment (1), and that resolution of RDS may be limited by the effects of the PDA. It has been shown that surgical ligation of the PDA as well as closure after administration of indomethacin is associated with reduced ventilatory and oxygen requirements $(6,7)$, and reduced incidence of bronchopulmonary dysplasia (8). Left to right shunting through the PDA increases pulmonary blood flow which may cause pulmonary edema with or without pulmonary venous hypertension, causing further derangements in the mechanics of breathing (9) and surfactant inactivation (10). Surfactant replacement in both the lamb (11) and baboon (12) has been shown to improve lung function but has been associated with reduced pulmonary vascular resistance, which increases pulmonary blood flow due to left to right shunting through the PDA. This may explain the acute improvement in pulmonary status with subsequent cardiopulmonary deterioration as shunt flow through the PDA increases. Thus, surfactant therapy appears to improve lung function, which then unmasks the effects of the PDA after the initial improvement in respiratory status.

The purpose of this study was to assess independently the mechanical function of the lungs and the time course of the closure of the PDA in premature infants treated with exogenous surfactant and in a control group given placebo. We hypothesized that although infants treated with surfactant would have improved lung mechanics, they would also have increased left to right shunt flow through the PDA, would have more symptoms attributable to PDA, and would need to be treated more frequently for the PDA than their controls.

\section{MATERIALS AND METHODS}

Sixty-one infants were enrolled in a prospective, controlled, and blinded clinical trial for the treatment of RDS with human amniotic surfactant after their parents signed an IRB-approved Human Subjects' Informed Consent. All infants were treated at one of the centers (University of California Medical Center, San Diego): details of the preparation of the human surfactant and its administration (FDA I.N.D. 26308 ) have been described (3). The gestational age of the infants ranged from 24 to $29 \mathrm{wk}$, and their birth wt from 450 to $1580 \mathrm{~g}$. All had pulmonary immaturity as demonstrated by analysis of amniotic fluid or tracheal aspirate obtained immediately after birth, showing a lecithin/sphingomyelin ratio of less than 2.6 (56/61 infants had a lecithin/ sphingomyelin ratio $\leq 2.0$ ) and absence of phosphatidylglycerol. Infants were excluded if they had malformations known to influence fetal lung development, such as oligohydramnios with 
renal dysplasia, fetal hydrops, evidence of amnionitis, or subsequent confirmed evidence of congenital infection. Informed consent was obtained from the parents for randomization before delivery and before sedation of the mother.

Infants were assigned to treatment or placebo immediately before birth by opening sealed envelopes which contained randomized assignments prepared before the start of the study. Infants at both centers were randomized together. Infants were stratified by gestational age (24-27 and 28-29 wk) and for multiple gestation. Singletons were randomized to three groups of equal probability. The first was given surfactant $(70 \mathrm{mg} / \mathrm{kg})$ at birth (prophylaxis). The second was treated only after they required mechanical ventilation (mean airway pressure $\geq 7.0 \mathrm{~cm}$ $\mathrm{H}_{2} \mathrm{O}$ ) and if their $\mathrm{Fi}_{\mathrm{O}_{2}}$ required for adequate oxygenation exceeded 0.5 , or if increases in peak inspiratory pressures of more than $5 \mathrm{~cm} \mathrm{H} \mathrm{H}_{2} \mathrm{O}$ above initial settings were necessary to maintain the $\mathrm{Pa}_{\mathrm{O}_{2}}$ above 50 torr (rescue). The third was given an injection of air (placebo) in a blinded fashion. Infants of multiple gestations were randomized with equal probability to prophylaxis or to rescue surfactant treatment.

Efforts were undertaken to blind all participants of the health care team to the treatment assignment. All infants were immediately intubated after birth (our standard procedure in infants of 25-29 wk of gestation), and treatment with surfactant or placebo was performed as described (3).

Routine neonatal intensive care was provided each infant. During the first $24 \mathrm{~h}$ of life, intravenous fluids were given (60 to $80 \mathrm{ml} / \mathrm{kg} / \mathrm{d}$ ) and fresh frozen plasma, albumin, or packed red blood cells were used to treat hypotension, poor perfusion, and acidosis. Infants with persistent hypotension were treated with dopamine infusions $(2.5$ to $5.0 \mu \mathrm{g} / \mathrm{kg} / \mathrm{min})$. The arterial $\mathrm{P}_{\mathrm{O}_{2}}$ and $\mathrm{P}_{\mathrm{CO}_{2}}$ were maintained at 50-70 torr and 40-60 torr, respectively, by adjustments of the $\mathrm{Fi}_{\mathrm{O}_{2}}$, and ventilatory pressures and time cycle settings. Ventilatory pressures and time cycle settings were measured at the proximal airway (Pneumogard Monitor, Novametrix, Wallingford, CT, or as measured by the Infant Star Ventilator, Infrasonics, San Diego, CA).

We determined the patency of the ductus arteriosus by Doppler ultrasound studies performed at 6 -h intervals until we found the ductus to be closed on two consecutive studies. Atrial and ventricular anatomy, left ventricular fractional shortening index, and shunt flow through the PDA were assessed from 2-dimensional echo-guided flow mapping (CFM) technique (Toshiba SSH-65 Color Doppler system, $5 \mathrm{MHz}$ short-focus transducer, pulse repetition frequency $4 \mathrm{kHz}$, frame rate $30 \mathrm{~Hz}$ ). To assess the amount and direction of ductal shunting, the pulmonary artery, ductus arteriosus, and aorta were visualized in a high left parasternal view. Areas in which the flow was toward the transducer were displayed in red; areas in which flow was away from the transducer were displayed in blue; and areas where there was turbulence, defined as a statistically significant variation of mean frequencies between scans in a set location, were displayed by adding green to the other colors. The blood flow in the PDA was usually seen as a stream of turbulent flow along the left anterior border of the pulmonary artery near the bifurcation, proceeding proximally toward the transducer. Right to left shunting was seen as blue flow from the pulmonary artery through the ductus arteriosus into the aorta (13). By using the spectral Doppler color-flow image, high velocities and turbulence detected near the PDA was a sensitive method to define the anatomic presence of the PDA, the magnitude of its shunt, or to declare with a high degree of confidence that it was closed. The decision to treat the PDA was made by the medical staff not involved with the surfactant protocol. The echocardiographic assessments of the PDA described above were usually available to the medical staff caring for the infant, but the results of serial assessments in any infant were not available to the medical staff.

Routine echocardiography was used to determine whether there was a large or small PDA shunt or if the PDA was constricted (13). Infants with a small PDA shunt or constricted
PDA were not treated. If a large left to right PDA shunt was demonstrated by routine echocardiogram and if there were signs of clinical deterioration due to the PDA and there were no contraindications to treatment with indomethacin, a first dose was administered by intravenous infusion $(0.2 \mathrm{mg} / \mathrm{kg})$. Infants with severe clinical deterioration and/or contraindications to treatment with indomethacin were treated by ligation. Infants were treated with a second and third dose $(0.1 \mathrm{mg} / \mathrm{kg}) 12$ and 24 $\mathrm{h}$ later if the PDA shunt was detected on subsequent routine echocardiogram and continuing clinical signs of deterioration. After this course of indomethacin treatment, infants with persistent PDA with congestive heart failure and ventilatory compromise underwent surgical ligation of the PDA.

The mechanics of breathing were measured at $6 \mathrm{~h}, 18 \mathrm{~h}$, and $30 \mathrm{~h}$ after birth. Infants were studied in the supine position when they were ventilated with the same pressures used for clinical management. Measurements were made with the same ventilator pressure and time cycle settings as were used for clinical care. No infant was receiving muscle relaxation or bronchodilators at the time of study.

We measured the mechanics of breathing by recording the transpulmonary pressure and airway flow at the endotracheal tube. Esophageal pressure was measured with a $1 \times 3 \mathrm{~cm}$ thinwalled latex esophageal balloon (14), placed in the midthoracic esophagus, which was connected to one side of a differential pressure transducer (Celesco Model LCVR, $\pm 50 \mathrm{~cm} \mathrm{H}_{2} \mathrm{O}$, Canoga Park, CA). The other side of this differential transducer was attached to the proximal port of the pneumotachograph. After placement of the esophageal balloon, its position and vol were checked by airway occlusion during spontaneous breathing efforts (15). Airway flow was measured with a Fleisch 00 pneumotachograph inserted between the connector of the endotracheal tube and the ventilator. The arms of the pneumotachograph were connected to a differential pressure transducer (Celesco Model LCVR, $\pm 2 \mathrm{~cm} \mathrm{H}_{2} \mathrm{O}$ ) with low compliance tubing. The pressure transducer was calibrated with a water manometer, and the pneumotachograph was calibrated with a rotameter. The amplitude frequency response of the pressure and flow measurement systems was flat to $20 \mathrm{~Hz}$.

The pressure and flow signals were amplified, digitized at a sampling rate of $60 \mathrm{~Hz}$, displayed on a video monitor, and stored for analysis with a computerized data acquisition system (16). During data acquisition, the endotracheal tube and the patient's head were carefully positioned to minimize leaks around the endotracheal tube. In several infants, we applied slight pressure over the trachea which eliminated leaks around the endotracheal tube. All mechanics measurements were performed during mechanical ventilation with ventilator pressures which were thought to be optimal for each infant's clinical condition.

Data analysis. We assessed the infants' oxygen requirements at the time of each measurement of mechanics of breathing and each echocardiographic study by calculating the a/A ratio (17). The infants' ventilatory requirements were assessed by measuring peak inspiratory and end-expiratory mean airway pressures at the time of these measurements.

Patency or spontaneous closure of the PDA and the frequencies of treatment of the PDA (indomethacin, ligation, or both) for surfactant-treated infants and controls were compared by Fisher's exact test. We compared the median arterial $\mathrm{pH}, \mathrm{P}_{\mathrm{O}_{2}}$, and $\mathrm{P}_{\mathrm{CO}_{2}}$ of infants treated with surfactant to controls, and we compared the median arterial $\mathrm{pH}$ and $\mathrm{P}_{\mathrm{CO}_{2}}$ of infants with spontaneous closure of the PDA to those requiring PDA treatment by Mann-Whitney U test.

We defined the time of PDA closure as the time of the echocardiographic study wherein the ductus arteriosus could not be visualized and no shunt flow could be demonstrated, and closure was confirmed by subsequent study. The median age at the time of closure was compared between infants treated with surfactant and controls by Mann-Whitney U test. We also compared the median age at the first treatment with indomethacin 
for the two groups by Mann-Whitney $U$ test and the frequency of the presence of a right to left shunt by Fisher's exact test.

We calculated the parameters of the mechanics of breathing by displaying the pressure and flow data with a screen editor and selecting the beginning, middle, and end of each breath. If a leak produced a discrepancy in the inspiratory and expiratory vol of more than $10 \%$, the data were rejected. We failed to obtain complete studies because of leaks around the endotracheal tube or technical problems with esophageal pressure measurements in 9 of the 61 infants. The gestational age, birth wt, and ventilatory status of these infants were not significantly different than infants in which we were able to complete the studies. Dynamic lung compliance, total pulmonary resistance, inspiratory work of breathing, and tidal vol were calculated for 5 to 10 breaths for each infant. The coefficient of variability averaged 8 and $16 \%$ for compliance and resistance measurements, respectively.

We compared the frequency of right to left shunting in surfactant-treated infants to controls using Fisher's exact test. We also compared the mean dynamic compliance, mean airway pressure, and the a/A ratio between infants with right to left and left to right shunts by ANOVA with Newmann-Keuls testing.

\section{RESULTS}

The distribution of surfactant treatment and treatments for PDA and its outcome are shown in Figure 1. We observed a PDA in all 61 infants enrolled in the study at 6 and $12 \mathrm{~h}$ of age. A total of 49 infants received surfactant: 30 were treated at birth (prophylaxis) and 19 were treated at $2.7 \pm 1.9 \mathrm{~h}$ of age (rescue). The greater number of infants treated with surfactant reflects the 12 pairs of twins enrolled, all of whom were randomized to surfactant treatment. Two infants who were randomized to receive rescue surfactant failed to meet the requirements for treatment. Their data were included in the treatment group as randomization was more important than the bias involved in our selection of the criteria for rescue therapy. The data were also analyzed with these infants excluded, and with these infants included in the control group, and the conclusions drawn were not changed. In terms of PDA therapy, one of these infants was

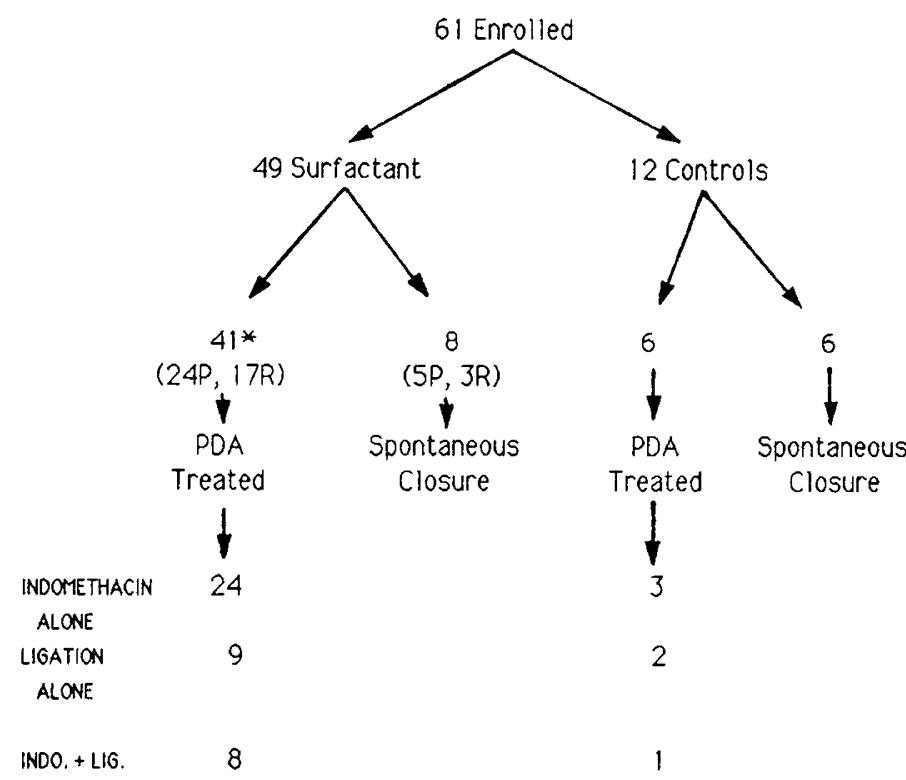

Fig. 1. Of 61 infants enrolled, 49 received surfactant $[30$ were treated prophylactically $(P)$ at birth and 19 were rescued $(R)$ after clinical deterioration]. Surfactant treatment was associated with more frequent overall treatment of the PDA $(p=0.02),{ }^{*}$ but not more frequent treatment with indomethacin, ligation alone, or ligation after indomethacin. There was no significant difference in frequency of PDA treatment among infants treated with surfactant at birth $(P)$ or those rescued $(R)$. treated with indomethacin and the other had spontaneous closure of PDA. Of the infants treated with surfactant, eight had spontaneous closure of the PDA and 41 required treatment-24 with indomethacin alone, nine with ligation, and eight with ligation after indomethacin. Of the 12 infants who were not treated with surfactant, six had spontaneous closure of the PDA and six required treatment--three with indomethacin alone, two with ligation, and one with ligation after indomethacin. Surfactant treatment was associated with more frequent overall treatment of the PDA $(p=0.02)$, but not with treatment with indomethacin or ligation alone $(p=0.2)$, or ligation after indomethacin.

The estimated power of our rejection of the hypothesis that surfactant-treated infants required more frequent treatment with indomethacin or ligation alone was 0.8 and 0.78 , respectively. Surfactant treatment did not alter the time course of spontaneous or induced closure of the PDA (Table 1). The average birth wt, gestational ages and male/female ratio were not significantly different between infants treated with surfactant and controls, or between infants who had spontaneous closure of the PDA, or who were treated with indomethacin or ligation. The age of the infants at the time of spontaneous closure was not significantly different between the groups $(47 \pm 23 \mathrm{~h}$ versus $27 \pm 15 \mathrm{~h}$, surfactant versus control, respectively, $p>0.2$ ). In addition, there was no difference in the average age at the time of the last study confirming the presence of the PDA. The first dose of the indomethacin was given at similar times in both groups of infants $(22 \pm 16 \mathrm{~h}$ versus $17 \pm 11 \mathrm{~h}$, surfactant versus controls, respectively); the PDA closed at a similar interval after the first dose in both groups $(29 \pm 18 \mathrm{~h}$ versus $25 \pm 9 \mathrm{~h}$, surfactant versus controls, respectively); and after infants in the groups received similar numbers of doses of indomethacin. The direction or magnitude of the PDA shunt demonstrated by echocardiographic studies in the first $12 \mathrm{~h}$ was not related to treatment with either indomethacin or surfactant.

The average dynamic lung compliance, mean airway pressure, and a/A ratio were not significantly different between infants treated prophylactically at birth or subsequently rescued. The data for all infants treated with surfactant were pooled for comparison with controls and for comparing the need for treatment of the PDA. The average dynamic lung compliances at 18 and $30 \mathrm{~h}$ for infants treated with surfactant were higher than controls, but this was not statistically significant (Fig. 2). Infants

Table 1. Surfactant treatment and closure or treatment of PDA*

\begin{tabular}{lcc}
\hline & Surfactant & Controls \\
\hline Infants with spontaneous closure & & \\
$\quad$ of PDA & & \\
Birth wt (g) & $961 \pm 247$ & $788 \pm 175$ \\
Gestational age (wk) & $27.5 \pm 1.3$ & $27.2 \pm 2.2$ \\
Sex (M/F) & $3 / 5$ & $3 / 3$ \\
Age at closure (h) & $47 \pm 23$ & $27 \pm 15$ \\
Infants treated with indometha- & & \\
$\quad$ cin & $953 \pm 185$ & $1246 \pm 402$ \\
Birth wt (g) & $27.4 \pm 1.2$ & $27.7 \pm 2.3$ \\
Gestational age (wk) & $11 / 13$ & $1 / 2$ \\
Sex (M/F) & $22 \pm 16$ & $17 \pm 11$ \\
Age at first indomethacin dose & & \\
$\quad$ (h) & $29 \pm 18$ & $25 \pm 9$ \\
Interval between first indo- & & \\
$\quad$ methacin dose and closure & & \\
$\quad$ (h) & & \\
Infants treated with ligation $\dagger$ & $904 \pm 240$ & $780 \pm 104$ \\
Birth wt (g) & $11 / 6$ & $25.7 \pm 1.2$ \\
Gestational age (wk) & $28 \pm 16$ & $3 / 0$ \\
Sex (M/F) & & $41 \pm 16$ \\
Age at ligation &
\end{tabular}

* All values are mean $\pm \mathrm{SD}$.

$\dagger$ Includes eight infants treated with indomethacin and ligation. 
with spontaneous closure of the PDA, however, had a significantly higher mean dynamic compliance than those who required treatment of PDA $(p<0.05,0.02,0.01$ at 6,18 , and $30 \mathrm{~h}$, respectively). The average oxygen requirement, as reflected in the a/A ratio, also was not significantly different between all infants treated with surfactant and controls, as shown in Figure 3. Infants with spontaneous closure, however, had a significantly higher average a/A ratio than infants requiring treatment of PDA ( $p<0.005,0.001$, and 0.025 at 6,18 , and $30 \mathrm{~h}$, respectively). The average mean airway pressure was not significantly different between all infants treated with surfactant and controls, as shown in Figure 4. Infants with spontaneous closure of the PDA were treated with significantly lower mean airway pressures $(p<$

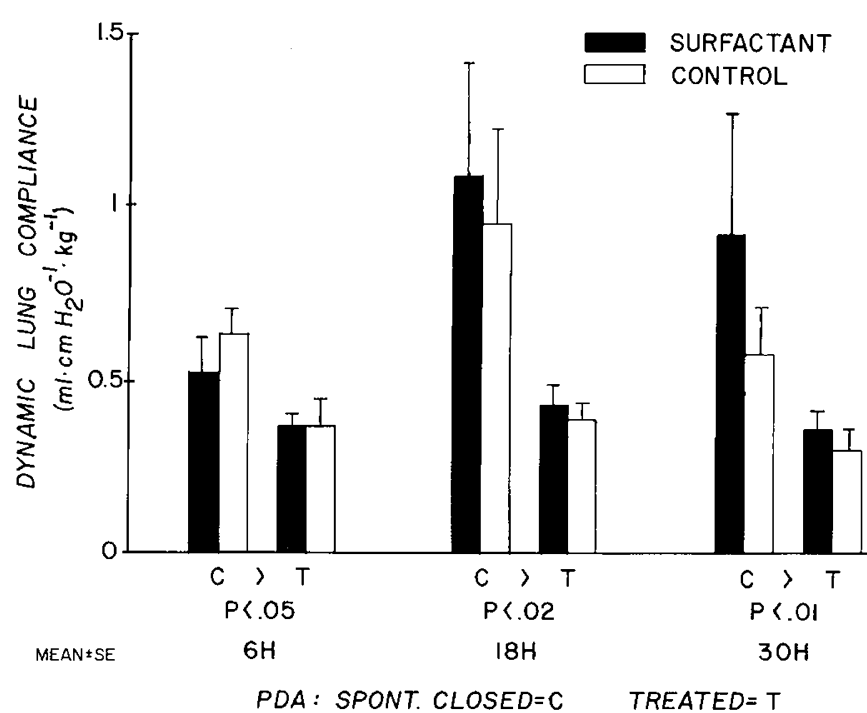

Fig. 2. Mean dynamic lung compliance at 6,18 , and $30 \mathrm{~h}$ of age, for surfactant-treated infants (black) and controls (white), and for infants with spontaneous closure of the PDA $(C)$ and those that required treatment $(T)$. Dynamic compliance was significantly lower in infants requiring PDA treatment at the three study times. Mean values for surfactant-treated infants were not significantly different from those of controls.

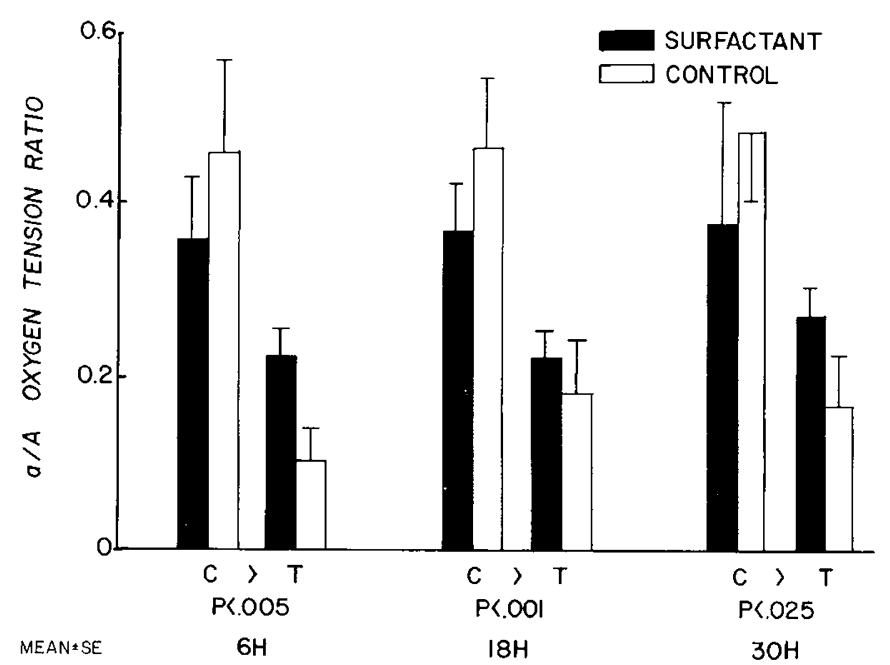

PDA : SPONT. CLOSED $=\mathrm{C}$ TREATED $=\mathrm{C}$

Fig. 3. Average a/A oxygen tension ratio at 6,18 , and $30 \mathrm{~h}$ of age, for surfactant-treated infants (black) and controls (white), and for infants with spontaneous closure of the PDA $(C)$ and those that required treatment $(T)$. Average a/A ratio was significantly lower in infants requiring PDA treatment at the three study times. Mean values for surfactant-treated infants were not significantly different from those of controls.

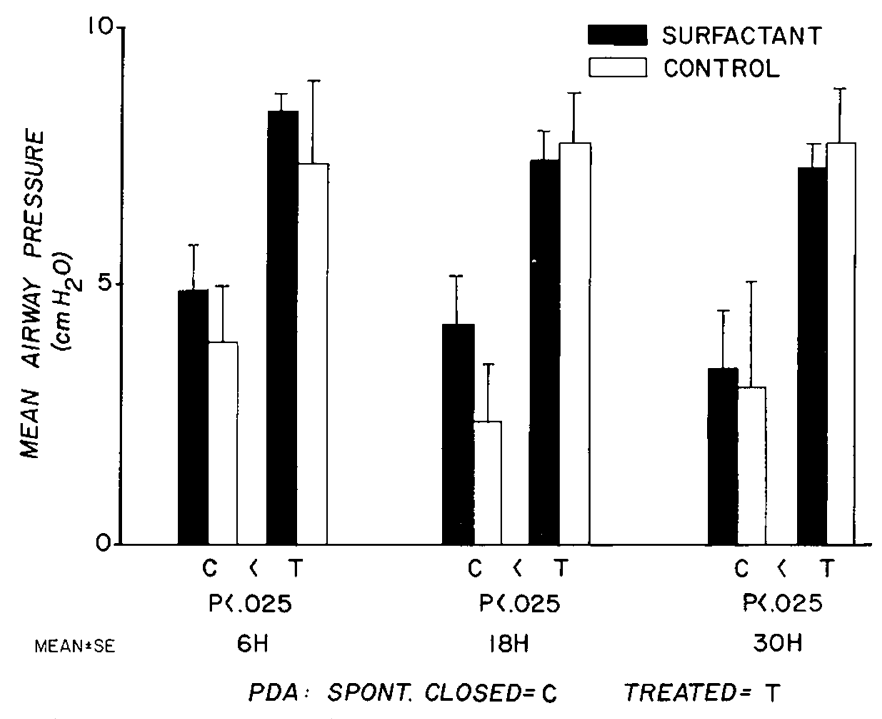

Fig. 4. Average mean airway pressures at 6,18 , and $30 \mathrm{~h}$ of age, for surfactant-treated infants (black) and controls (white), and for infants with spontaneous closure of the PDA $(C)$ and those that required treatment $(T)$. Average mean airway pressure was significantly higher in infants requiring PDA treatment at the three study times. Mean values for surfactant-treated infants were not significantly different from those of controls.

0.025) (Fig. 4) than infants needing treatment of PDA. The median arterial $\mathrm{pH}$ of infants with spontaneous closure was not significantly different from that of infants who required PDA treatment $(6 \mathrm{~h}: 7.37$ versus $7.32,18 \mathrm{~h}: 7.36$ versus $7.31,30 \mathrm{~h}$ : 7.32 versus 7.29 , respectively), or between infants treated with surfactant and controls. There were no differences noted between these groups (surfactant versus control or spontaneous closure versus treatment of PDA) for total pulmonary resistance, tidal vol, or the inspiratory work of breathing at these times.

In 10 infants, the mechanics of breathing were measured before and after closure of the PDA. Dynamic lung compliance increased and mean airway pressure was lower in six of these 10 infants after closure. The a/A ratio was increased in five of these 10 infants after closure; however, these differences were not statistically significant.

Shunt flow was visualized from the pulmonary to aortic end of the PDA (usually turbulent during systole) in 12 infants, which changed to a left to right shunt by $24 \mathrm{~h}$ of age in each infant. The mean dynamic compliance of infants with right to left shunt was significantly lower than that of infants with left to right shunts at 6 and $18 \mathrm{~h}(p<0.05)$. Infants with right to left PDA shunt required treatment with higher mean airway pressures at $18 \mathrm{~h}\left(7.8\right.$ versus $\left.6.5 \mathrm{~cm} \mathrm{H} \mathrm{H}_{2} \mathrm{O}, p<0.01\right)$ and higher inspired oxygen tensions as reflected by lower a/A ratios $(0.12$ versus $0.37, p<0.005$ ), but their arterial $\mathrm{P}_{\mathrm{O}_{2}}$ values were similar. The differences in these treatment parameters were not significant at 6 or $30 \mathrm{~h}$ of age. Treatment with surfactant was not associated with the presence of a right to left shunt: nine of the 12 infants were treated with surfactant and three were not $(p=0.034)$.

\section{DISCUSSION}

In our study, spontaneous closure of the PDA was associated with mild lung disease, as indicated by significantly higher dynamic lung compliance and lower treatment parameters. Although all infants had pulmonary immaturity as defined by the lung lipid profile and chest radiograph, their lung disease represented a wide range of pathophysiology. The dynamic compliance, an indicator of the mechanical stability of the lung, depends both on the structural integrity of the lung and the maturity of the surfactant system. Our observation that infants with spontaneous closure of the ductus appear to have greater stability of 
the lungs, even when the ductus was patent in all infants at $6 \mathrm{~h}$, suggests that the maturation of the ductus arteriosus parallels that of the lung in these infants. Pulmonary edema does not appear to be as important a determinant of mechanical stability as lung maturity. The presence of a right to left shunt, although associated with the use of higher mean airway pressures and $\mathrm{Fi}_{\mathrm{O}}$ requirements at $18 \mathrm{~h}$, was not associated with significantly lower compliance values or to greater treatment parameters at 6 and $30 \mathrm{~h}$. The insignificant changes in lung compliance and a/A ratio with PDA closure further supports the concept that lung maturity, rather than pulmonary edema secondary to PDA shunt, is a more important determinant of the mechanical stability of the lungs.

Surfactant therapy was associated with more prevalent overall perceived need to treat the PDA, but not with greater prevalence for any particular treatment modality. Although PDA treatment was more prevalent after surfactant, surfactant treatment did not appear to interfere with the action of indomethacin in that the interval between treatment with indomethacin and closure was not prolonged. This may have been due to the bias produced by patient selection, which should have made ductal patency and its treatment more frequent in the surfactant treatment group, as 19 of the infants were randomized to surfactant treatment because they experienced mechanical ventilation and clinical deterioration. Thus, we expected the rescued infants to have more severe lung disease that should have been associated with delayed closure of the PDA and more prevalent treatment. We did not observe a difference in the rate of spontaneous closure between infants treated at birth or as a rescue, as the number of infants treated with surfactant whose PDA closed spontaneously was small (eight infants). This may also explain the similarity in the MAP and a/A ratios between the surfactant-treated and control infants.

Our finding of more frequent PDA treatment in surfactanttreated infants is similar to early reports $(1,5)$. The present study differs from our earlier report showing no difference (3) in that the present study was performed in one of the two centers, and infants were randomized to rescue treatment in addition to control and prophylaxis. Our present findings differ from the study of Enhorning et al. (2) and Gitlin et al. (4) because of the randomization of infants to the three groups. The sizes of our two surfactant groups were too small to make inferences as to how the prophylactic surfactant group differed from rescue, and how both differed from the infants described in these latter two studies.

The outcome of the PDA and its treatment in our infants were similar to reported results. The infants' spontaneous PDA closure rate was $23 \%$, and the rate of successful treatment with indomethacin $(44 \%)$, and need for both indomethacin and ligation $(15 \%)$ were similar to large collaborative observations $(34,46$, and $20 \%$, respectively) (18). Our findings also are consistent with the description of cardiovascular effects of surfactant treatment in lambs by Jobe et al. (19). We did not detect an increase in the pulmonary blood flow in infants who received surfactant as detected by Doppler echocardiogram, unlike that observed by microsphere injections in lambs (11) or baboons (12).

Our results are dissimilar to those of studies in baboons as we did not see a significant improvement in the lung mechanics in spite of improved oxygenation in the 12 infants in which measurements were performed before and after surfactant treatment. This study was not designed to detect changes in mechanics after surfactant rescue: more frequent measurements would have been needed at specific intervals relative to surfactant treatment. Our results may reflect differences between species or in the effectiveness of the surfactant or, more likely, the fact that the $\mathrm{pH}$ and $\mathrm{P}_{\mathrm{CO}_{2}}$ of our infants were controlled more closely than in the animal studies. The increased pulmonary blood flow seen in those studies may have been due largely to the improved $\mathrm{pH}$ (20) after the surfactant treatment ( 7.26 versus 6.92 , surfactant versus control, Ref. 11).
The similar compliance values in surfactant treated infants and controls suggests that the lungs are overdistended by the pressure of routine mechanical ventilation, leading to little change in compliance after surfactant therapy. The improvement in oxygenation may have been due to increased lung vol (which is associated with a decrease in pulmonary vascular resistance) after surfactant treatment, which we did not measure. The values of compliance that we measured were similar to those recently reported during mechanical ventilation (21), and lower than those measured in infants who were spontaneously breathing on continuous positive airway pressure, which further supports the hypothesis of lung overdistension. Furthermore, we estimate the power to detect the difference in lung compliance between the surfactant-treated infants and controls to be 0.45 , based on the coefficient of variability, the differences we observed between the groups, and the limited number of control infants. This difference in the observed compliance may have been significant with a power of 0.8 if we studied 40 infants in each group.

Our finding that a right to left shunt pattern was associated with lower dynamic lung compliance, higher ventilatory pressures, and higher oxygen requirements suggests that the underinflated or underventilated lung has an increased pulmonary vascular resistance that promotes right to left shunting through the PDA. Conversely, left to right shunting would be expected in infants with less severe lung disease because the pulmonary vascular resistance would be reduced. We did not observe, however, an increased incidence of left to right shunting or a larger magnitude of left to right shunting in infants who were treated with surfactant.

In summary, surfactant treatment of these very immature infants was associated with more prevalent clinical and echocardiographic findings of the PDA which justified treatment. The spontaneous closure of the ductus, however, was instead associated with mechanical stability, or structural maturity of the infants' lungs, independent of surfactant replacement therapy. Measurements of the dynamic lung compliance may be a predictor of spontaneous PDA closure in preterm infants with RDS.

Acknowledgments. The authors acknowledge the technical assistance of Wade Rich, RRT, and Larry Schellenberg, RRT, in performance of the measurements of mechanics of breathing, and Mary Cobb for her patient and accurate preparation of the manuscript.

\section{REFERENCES}

1. Fujiwara T, Maeta H, Chida S, Morita T, Watabe $Y$, Abe $\Upsilon 1980$ Artificial surfactant therapy in hyaline-membrane disease. Lancet 1:55-59

2. Enhorning G, Shennan A, Possmayer F, Dunn M, Chen CP, Milligan J 1985 Prevention of neonatal respiratory distress syndrome by tracheal instillation of surfactant: a randomized clinical trial. Pediatrics 76:145-153

3. Merritt TA, Hallman M, Bloom BT 1986 Prophylactic treatment of very premature infants with human surfactant. N Engl J Med 315:785-790

4. Gitlin JD, Soll RF, Parad RB, Horbar JD, Feldman HA, Lucey JF, Taeusch HW 1987 Randomized controlled trial of exogenous surfactant for the treatment of hyaline membrane disease. Pediatrics 79:31-37

5. Raju TNK, Vidyasagar D, Bhat R, Sobels D, McCulloch KM, Anderson M Maeta H, Levy PS, Furner S 1987 Double-blind controlled trial of singledose treatment with bovine surfactant in severe hyaline membrane disease. Lancet 1:651-656

6. Kitterman JA, Edmunds LH Jr, Gregory GA, Heymann MA, Tooley WH, Rudolph AM 1972 Patent ductus arteriosus in premature infants: incidence, relation to pulmonary disease and management. N Engl J Med 287:473477

7. Mahony L, Carnero V, Brett C, Heymann MA, Clyman RI 1982 Prophylactic indomethacin therapy for patent ductus arteriosus in very-low-birth-weight infants. N Engl J Med 306:506-510

8. Merritt TA, Harris JP, Roghmann K, Wood B, Campanella V, Alexson C, Manning J, Shapiro DL 1981 Early closure of the patent ductus arteriosus in very low-birth-weight infants: a controlled trial. J Pediatr 99:281-286

9. Johnson J, Permutt S, Sipple J, Salem ES 1964 Effect of intra-alveolar fluid on pulmonary surface tension properties. J Appl Physiol 19:769-777

10. Ikegami M, Jobe A, Jacobs H, Lam R 1984 A protein from airways of premature lambs that inhibits surfactant function. J Appl Physiol 57:11341142

11. Clyman RI, Jobe A, Heymann M, Ikegami M, Roman C, Payne B, Mauray F 1982 Increased shunt through the patent ductus arteriosus after surfactant replacement therapy. J Pediatr 100:101-107 
12. Vidyasagar D, Maeta H, Raju TNK, John E, Bhat R, Go M, Dahiya U, Roberson Y, Yamin A, Naurla A, Evans M 1985 Bovine surfactant (Surfactant TA) therapy in immature baboons with hyaline membrane disease Pediatrics 75:1132-1142

13. Swensson RE, Valdes-Cruz LM, Sahn DJ, Sherman FS, Chung KJ, Scagnelli S, Hagen-Ansart S 1986 Real-time Doppler color flow mapping for detection of patent ductus arteriosus. J Am Coll Cardiol 8:1105-1112

14. Beardsmore CS, Helms P, Stocks JS, Hatch DJ, Silverman M 1980 Improved esophageal balloon technique for use in infants. J Appl Physiol 49:735-742

15. Milner AD, Saunders RA, and Hopkin IE 1978 Relationship of intraesophageal pressure to mouth pressure during measurement of thoracic gas volume in the newborn. Biol Neonate 33:314-319

16. Heldt GP, Targett RC, and Mcllroy MB 1982 A microcomputer-based data acquisition system for physiologic studies of the newborn. In: Harris TR, Bahr JP (eds) The Use of Computers in Prenatal Medicine. Praeger, New York, pp 353-362
17. Gilbert R, Keighley JF 1974 The arterial/alveolar oxygen tension ratio: an index of gas exchange applicable to varying inspired oxygen concentrations. Am Rev Respir Dis 109:142-145

18. Gersony WM, Peckham GJ, Ellison RC, Miettinen OS, Nadas AS 1983 Effects of indomethacin in premature infants with patent ductus arteriosus: results of a national collaborative study. J Pediatr 102:895-906

19. Jobe A, Jacobs H, Ikegami M, Jones S 1983 Cardiovascular effects of surfactant suspensions given by tracheal instillation to premature lambs. Pediatr Res 17:444-448

20. Schreiber MD, Heymann MA, Soifer SJ 1986 Increased arterial pH, not decreased $\mathrm{PaCO}_{2}$, attenuates hypoxia-induced pulmonary vasoconstriction in newborn lambs. Pediatr Res 20:113-117

21. Davis JM, Veness-Meehan K, Notter RH, Bhutani VK, Kendig JW, Shapiro DL 1988 Changes in pulmonary mechanics after the administration of surfactant to infants with respiratory distress syndrome. $N$ Engl $J$ Med 319:476-479 